\title{
Interdisciplinary and Globalisation Issue at the International Conference for Interdisciplinary Studies 2014 (ICIS) in South Korea
}

\author{
Prayanto Widyo $\mathrm{H}$
}

Globalization drives a country becomes smaller or narrower due to the ease of interaction between countries, be it in trade, technology, information exchange, and lifestyle. Globalization is a worldwide intensification of social relations that connect between the events that occur in different sites with one another and cause many changes (Smith and Baylis, 2001).

Globalization caused by rapidly advancement of knowledges and sciences in information and communication technology. The information and communication technologies play the role in the process of agreements held between countries that are closely interwoven with various things including transactions in the field of economy.

Globalization becomes an important issue in the International Conference for Interdisciplinary Studies (ICIS 2014) in Busan, South Korea. As stated by Taehee Kim, $\mathrm{PhD}$, who is the executive director of International Cooperation, "This conference aims to invite international institutions of various disciplines and hoped to provide power to the national economy. The current economic character is not easily predictable and very quickly turned like a thunderbolt. All of the things cannot be separated from the development of the various disciplines that do exist."

ICIS 2014 was held on September 22 and 23, 2014. The goal of this conference is to bring together researchers from academia and practitioners to share ideas, problems, and solutions. This conference provided many opportunities for researchers to present the latest research findings and describe emerging technologies, new research problems, and directions in globalization issues. The conference seeks to contribute and present novel research results in all aspects of stregthening the country's competitiveness in the globalization.

In the current globalization, where bounderies among countries are obscured or borderless, where information is moving quickly, each country has its own challenges to improve their countries' strengthening capabilities in many areas such 
as Technology, economics and business, exact and social sciences, culture and gender, law, hospitality and tourism, linguistics, communications and arts and design.

In light of this, several universities in Indonesia, in coopertaion with Youngsan University in Korea and its association with eight countries in the world, are planning to carry out an International Conference called, "International Conference for Interdisciplinary Studies (ICIS) : Strengthening National Competitiveness through cooperation in the Era of Globalization." The conference will be the first conference designed mitigate these challenges.

The President of Youngsan University Guwuck Bu, LLD as the host of the conference says that the value of creative attention and 'convergence' as a concept to make the changes. Convergence is a new value and solutions in the world competition. This is the concept and context that will be discussed at this conference. Exchange of knowledges and information between disciplines become the main concern. And it is expected to be the contribution and the strength of the national economy.

This conference is considered appropriate to the conditions that developed at this time, both nationally and internationally where the issues of global (globalization) requires interdisciplinary studies. The conference which held in South Korea is the first conference. This activity is planned to be implemented every year. For the International Conference for Interdisciplinary Studies 2014 (ICIS 2014) on the theme: Strengthening National Competitiveness through Cooperation in the Era of Globalization. ICIS 2014 held on 22-23 September 2014 held at Youngsan University, Busan, South Korea.

Busan is the second largest and most important city in South Korea after Seoul. Busan is a port city and metropolitan which is located in the southeast of South Korea. The city is designed by South Korean government as a tourist spot of foreign exchange from around the world that is increasing every year. Young Sun Sin as the Ambassador for international relations of Busan Metropolitan City in his speech said that the conference was perfectly held at this place because Busan is a city where trade, ports, logistics, and strongest financial in ASIA.

The conference is conducted in cooperation between the two countries, Korea and Indonesia are represented by a university from South Korea, Youngsan University, and several universities from Indonesia; Padjadjaran Bandung, UNIKOM Bandung, Bandung UNPAS, and UPI Bandung. The conference was followed and involved 107 presenters who were coming from many countries such as Indonesia, Korea, Japan, Thailand, the Philippines, Taiwan, Malaysia, Sudan, and Dubai.

Participants/speakers of 107 people who had different background of disciplines, raging from masters, doctorals students and lecturer. The speakers convey their ideas or research's results to the emerging issues at that time, both on economic issues, technology, communication, social, artistic, and political. The presentations of the conference was divided into 10 sessions with 10 rooms. Those tenth session included: marketing business sessions; business management, entrepreneurial business, finance; accounting and aministrasi; education and HRD; IT, arts and futures; social and legal 
knowledge; Globalization; social and information; and the last was tourism. Each session consists of between 8 to 13 people with 2 reviewers. Its implementation was technically made with panel system consisting of three or four speakers.

At session 9 consisted of 13 participants/speakers were divided into three panels. One panel comprised between 4-5 participants/ presenters to focus on the discussion on arts, communication, and management. This session was specifically discussing about globalization. Each speaker was given the opportunity to present his paper for 10-15 minutes, followed by a question and answer of the reviewer and the inter-speaker and audiences.

Hence, it can be concluded that globalization and interdisciplinary become a very important part in the conference. It is inevitable that the constantly evolving dynamics of international relations in line with scientific developments in various fields or disciplines. And the international relations between countries or between individuals from different countries, either in the form of political relations, culture, and economy, where each field has the important role that all of the necessary support interdisciplinary academic study. 